\title{
APPROACHES TO EVALUATING EFFICIENCY AND QUALITY OF INTEGRATED HEALTH CARE: STATE OF THE EVIDENCE
}

\author{
IGA RUDAWSKA
}

\begin{abstract}
A B S T R A C T
This paper investigates the outcomes of integrated health care model in terms of its economic efficiency and quality. The quality refers to subjective assessments of a patient, measured by a satisfaction indicator, as well as to the health benefits to a patient, measured by health status.

A systematic literature review has been applied to study the results of care coordination. The author performed the ordered analysis of existing research evidence, based on peer-reviewed literature available on health science and business databases.

The model of integrated health care delivery seemed to have positive effects on the quality of care. This encompasses mainly the quality of life, functional status, health outcomes, and process outcomes. The equal positive impact of integrated health programmes on economic efficiency has not been revealed. Only $15 \%$ of the effects reported in the reviews have been significant.

The work contributes to the worldwide debate dedicated to the impact of integrated health care programmes. The gathered research evidence concerning positive influence on costs remains unclear. It might require further investigations. The work also revealed some significant gaps that are prevalent in the field of standardized instruments of measurement referring to integration outcomes, including quality and efficiency over time at levels of the system, programme, provider, and patient.
\end{abstract}

KEY WORDS

integrated health care, performance measurement, quality improvement, cost containment

Corresponding author:

Iga Rudawska

Department of Business Analysis and Strategy, Faculty of Economics and Management, University of Szczecin

e-mail: igita@wneiz.pl

\section{INTRODUCTION}

Health care integration is a phenomenon, which apart from many enthusiasts, has also generated a sizeable group of sceptics or even critics. Their attention is drawn to the results of the application of care models based on Wagner's idea. Traditionally, the main areas of interest include quality and efficiency as well as the relationship between them in operating care.
It is worthwhile remembering the fundamental reason behind the increase in the interest in integrated health care, which was based on the desire to achieve higher efficiency in the management of available but limited resources as well as better results in their use. The relationship between efficiency and quality is clearly evident in integrated health care. It should be noted that ensuring quality increases therapy effectiveness, which results in better health outcomes 
for a patient and at the same time affects care costs (Sobczak \& Grudziąż-Sękowska, 2011, p. 156). The improvement in the quality of integrated health care has to contribute to generating direct savings both on the micro-scale (individual service providers) and the macro-scale (the entire system), chiefly resulting from reduced duplication of research and elimination of unnecessary procedures as well as inessential or inadequate resources. Improved quality additionally translates into long-term results, manifested through the holistic perspective, including avoidable or diminishable indirect costs of diseases, such as those emerging outside of the health care sector, in the social security system.

On the other hand, quality improvement requires substantial expenditure, which in integrated health care models is chiefly related to information and IT systems as well as organisational changes, such as the efficient location of medical equipment for the use by personnel. Under such circumstances, concerns are voiced regarding the implementation costs of integrated information and communication systems as well as their actual impact on achieved results. Typically, they are considered in respect of three dimensions:

- from the standpoint of health benefits to a patient, measured by health status, and in the long-term by the quality of life,

- from the standpoint of economic efficiency, most often expressed through costs incurred,

- from the standpoint of subjective assessments of a patient, measured by a satisfaction indicator.

The three above-listed dimensions most frequently feature in research on the effects of integrated health care, although the extent of the use of detailed indicators may vary. As such, they have been used in the proposed study.

\section{LITERATURE REVIEW}

Integrated health care is gaining more attention in all OECD countries. It is also on the top of the agenda of many international bodies such as the World Bank or the World Health Organization (WHO). The popularity of this idea has led to numerous studies that focused on the issue of co-ordination of the health care delivery process. The WHO European Office for Integrated Health Care Services conducts several projects devoted to this subject, for example, „Home Health Care”, „Linking Levels of Care”, „Primary Health Care”, „Human Resource Development”,
„Hospital Management”, or „Telemedicine” to mention but a few (Rudawska, 2013).

The phenomenon of integrated health care is associated with the provision of health care services through the coordination of different activities, such as diagnostics, therapy, rehabilitation, and health promotion, with the patient being the final beneficiary (Stranberg-Larsen \& Krasnik, 2009). A coherent set of services is planned, managed and delivered to individual service users across a range of health care organisations and by a range of co-operating professionals (Hardy et al., 2003, p. 10). The authors indicate that, in practice, integrated care appears in a variety of forms, for example, "shared care", „transmural care”, „integral care”, „disease management”, „intermediate care”, „comprehensive care”, or „continuing care”, partly reflecting differences in the scope, approach and different countries of origin. In a similar vein but focusing on the system approach, another group of researchers proposes to define the term „integrated” as a coherent set of methods and models on the funding, and the administrative-, organisational-, service deliveryand clinical levels designed to create connectivity, alignment and collaboration within and between the cure and care sectors (Koder \& Spreeuwenberg, 2002, p. 3). Furthermore, an element of integrated care is usually defined as an activity concerning realization, improvement, innovation or sustainability of integrated health care, based on the quality continuum of Feussner (Feussner et al., 2000).

It is generally believed, that integrated health care results in increased quality and effectiveness of care, at the same time being cost-effective or even costsaving (Van Raak et al., 2003). Although many authors do agree that integrated care is a promising solution, they indicate the need for the dialogue and debate about the need for economic evaluation of such arrangements (Vondeling, 2004, p. 1). Some researchers warn against having expectations of this health care model as they may be unrealistic, and support a measurable approach (Berenson \& Howell, 2009; Brown, 2009). This paper fits this trend. Its purpose is to summarise and discuss the outcomes of integrated health care in terms of quality and efficiency of this model. 


\section{RESEARCH METHOD}

A systematic literature review is a rigorous evaluation and synthesis of the research results reported in the literature. As a research method, it aims to provide managers and decision-makers with a synthesis of current evidence-based knowledge (Lavis et al., 2005, pp. 35-48; Lomas, 2005, pp. 55-71). Usually, a systematic literature review consists of several stages, with the intention to focus on ensuring the following (Bravata et al., 2005, pp. 105665; Brereton et al., 2007, pp. 571-83):

- the research is adequate to target users,

- the top quality studies are incorporated in the synthesis,

- diverse research is included, covering both qualitative and quantitative findings,

- the study includes peer-reviewed sciences and databases,

- analysis, interpretation, and synthesis of the evidence is valid,

- replicability principle of the scientific method is reflected.

A systematic literature review proves to have many advantages for planners and decision-makers. First of all, it lets them compare different findings and provides them with the synthesis of the challenges of the studied processes, models or strategies (Lavis et al., 2005, pp. 35-48). Secondly, it is time-saving and provides easier access to evidence-based information (Lavis et al., 2006, pp. 21-33).

The systematic literature review of peer-reviewed business science and health literature has been applied to meet the research purpose. High-quality databases, including Web of Science, Ebsco, Medline, and Cochrane Collaboration were used as a source of knowledge. The literature was searched in order to identify outcomes of integrated health care model, in terms of its efficiency, patient satisfaction, and clinical impact. Seven specific criteria have been applied: health results, quality of life, patient satisfaction, mortality rate, hospitalisation rate, process changes, and costs.

This paper summarizes the effects of integrated health care on the grounds of systematic literature review, which constitutes a method of ordered analysis of existing research results. Therefore, it is an attempt to collate research reports in such a manner so that an objective and representative image of the examined phenomenon is achieved. However, despite maintaining objective qualification criteria of the subjects analysed in the research, one needs to realize that the obtained results are strongly determined by the context, in which the analysed phenomena occurred.

The paper is based on a research conducted within the scope of a research project entitled: „The methodology of assessing patient care quality in integrated health care", financed by the National Science Centre of Poland (DEC-2012/05/B/ HS4/02213).

\section{RESEARCH RESULTS}

The presented systematic literature review concerns the publications on integrated health care programmes. Databases were searched using the following keywords: disease management, patient care management, patient-centred care, health planning, and delivery of integrated health care. Out of 350 works selected on these grounds, 13 studies that were qualified for further analysis included meta-analyses, concerning integrated care programmes, addressed to populations of adult patients. Six of the selected studies regarded patients suffering from coronary vessel diseases, two - from diabetes, another three were patients with chronic conditions, and the remaining ones involved individual cases of sufferers from rheumatoid arthritis, heart attack, and chronic lung failure. All of the cited studies adopted the definition of integrated care as worded by Mur-Veeman (2008, p. 173), which is a process-based view as the interpretation guideline for their consideration.

The Table 1 demonstrates that the improvement of the functional health condition of patients covered by the programme is the most frequently reported beneficial effect of integrated care programmes (in the case of only one meta- analysis, the trend occurred to be statistically significant). It proves high clinical quality understood as a correct diagnosis, the adequacy of implemented medical procedures, or the efficiency of undertaken pharmacotherapy. Improvement in the quality of life of a patient corresponds to positive health effects. This was observed in six out of all of the conducted synthesizing studies, but the trend was not statistically significant in neither of them. Moreover, only one study concerning patients after a heart attack showed a statistically significant drop in the mortality rate. In the remaining cases, in which this dimension of results was analysed, the mortality rate did not lend itself to unambiguous evaluation, which means that 
Tab. 1. Review of studies on the outcomes of integrated care programmes in terms of seven criteria

\begin{tabular}{|c|c|c|c|c|c|c|c|}
\hline $\begin{array}{c}\text { AUTHOR(S) OF THE } \\
\text { META-ANALYSIS }\end{array}$ & $\begin{array}{l}\text { HEALTH } \\
\text { RESULTS } \\
\end{array}$ & $\begin{array}{l}\text { QUALITY } \\
\text { OF LIFE }\end{array}$ & $\begin{array}{c}\text { PATIENT } \\
\text { SATISFACTION }\end{array}$ & $\begin{array}{c}\text { MORTALITY } \\
\text { RATE } \\
\end{array}$ & $\begin{array}{c}\text { HOSPITALISATION } \\
\text { RATE }\end{array}$ & $\begin{array}{l}\text { PROCESS } \\
\text { CHANGES }\end{array}$ & Costs \\
\hline $\begin{array}{l}\text { Ferguson } \\
\text { \& Weinberger }\end{array}$ & + & + & + & & & & ? \\
\hline Moser & + & + & & & - & & - \\
\hline Norris et al. & + & & & & & + & \\
\hline Philbin & + & + & + & & - & & ? \\
\hline Renders \& Wagner & + & & & & & + & \\
\hline Rich & + & + & + & ? & $-*$ & + & - \\
\hline Windham et al. & + & + & & $?$ & - & + & $?$ \\
\hline Badamgarav et al. & $?$ & & & & & & \\
\hline McAlister et al. (a) & + & + & & ? & $-*$ & & - \\
\hline McAlister et al. (b) & $+^{*}$ & & & ? & $-*$ & & - \\
\hline Sin et al. & & & & ? & $?$ & & \\
\hline SUTC & & & & $-*$ & & & \\
\hline Weingarten et al. & & & & & & $+*$ & \\
\hline
\end{tabular}

Legend: ? = ambiguous effect, - = downward trend (in over half of the analysed studies), $+=$ upward trend (in over half of the analysed studies), $*$ = the trend is statistically significant

Source: author's elaboration on the basis of (Windham et al., 2003; Ferguson \& Weinberger, 1998; Moser, 2000; Norris et al., 2002; Philbin, 1999; Renders et al., 2001; Rich, 1999; Badamgarav et al., 2003; McAlister et al., 2001a; McAlister et al., 2001b; Sin et al., 2003; SUTC, 2007; Weingarten et al., 2002).

the percentage of results favouring integrated programmes was balanced by the percentage of results of the opposing tendency.

Patient satisfaction, despite being a subjective measure of the experienced service quality, is strongly linked to the achieved health results. In the metaanalyses of the effects of integrated care programmes, in which these issues were considered, a positive trend emerges. Therefore, the integration of health care has a beneficial impact on the degree of the satisfaction experienced by patients. Whereas, its measurement ought to be combined with the implementation of the idea of patient-centred care, in which the opinions of those patients constitute a significant element of system's quality evaluation.

Five out of all of the considered meta-analyses examined the issue of process quality understood as a provider's monitoring of, complying with and adapting to procedural guidelines and protocols. All of the systematic literature reviews indicate a positive trend in respect of integrated care programs, but only one of them evaluates the achieved effect as being significant.

Positive effects expected of health care integration, involving the more rational use of resources, constitute a material argument in debates on health care integration. Since hospital care is typically the most expensive, researchers focus their attention on the duration of hospitalization. In the group of investigated meta-analyses, six demonstrated a downward trend of the length of hospital stays as well as a decrease in rehospitalisation with regard to patients included in integrated care programs. In the case of three of those analyses, the trend was significant. In turn, the economic effects of implemented programmes were evaluated in terms of outlays incurred. Four out of seven meta-analyses reported beneficial cost effects, understood as a cost reduction achieved as a result of integrative processes.

\section{DISCUSSION OF THE RESULTS}

Sceptics of health care integration claim that the savings made by integration are merely ,vain hopes" (Leutz, 1999, p. 89). Some results of other synthetic literature reviews seem to be in favour of such conclusions. For example, the synthetic literature review conducted by Powell-Davies et al. (2008, pp. 65-68) comprised a total of 85 randomized experimental and evaluative studies, the subject of which was health care integration with the participation of primary level (between primary health care and specialist outpatient care, between primary health care and hospitals, between primary health care and long-term care, and within primary health care). Selected studies concerned the USA, Australia, the United Kingdom, the Netherlands, 
New Zealand and Canada. In the majority of cases, the target group of integrated health care included patients with chronic conditions. The studies were selected using the following key words: „integration”, "coordination", "primary health care" and „multidisciplinary care”.

Positive cost-related effects were recorded with regard to the coordination of clinical activities in $1 / 5$ of examined cases that analysed the same issues (Tab. 2 ). In the remaining types of strategies, cost-related effects were even less evident, while the overall percentage of studies reporting a positive impact of integration on costs was below $20 \%$ (Tab. 2). of treated patients, yielding positive health effects, articulated in over half of the selected studies. This effect was most evident in the case of strategies oriented at the change of the relationship between providers (Tab. 2). Furthermore, the strategies occurred to have been the most effective in terms of improvement of patient satisfaction. In the remaining cases, the interventions appeared to have had a favourable influence on health results, but at the same time, they were less effective in building patient satisfaction and vice versa.

Ofman's team also conducted a meta-analysis of 102 papers, dedicated to the evaluation of effects

Tab. 2. Review of studies regarding the effects of integrated health care in the context of areas of intervention

\begin{tabular}{|c|c|c|c|}
\hline INTEGRATION STRATEGIES (AREAS OF INTERVENTION) & $\begin{array}{c}\text { PERCENTAGE } \\
\text { OF STUDIES } \\
\text { REPORTING } \\
\text { POSITIVE } \\
\text { INFLUENCE OF } \\
\text { INTEGRATION ON } \\
\text { HEALTH RESULTS } \\
\text { [\%] }\end{array}$ & $\begin{array}{c}\text { PERCENTAGE } \\
\text { OF STUDIES } \\
\text { REPORTING } \\
\text { POSITIVE } \\
\text { INFLUENCE OF } \\
\text { INTEGRATION } \\
\text { ON PATIENTS' } \\
\text { SATISFACTION } \\
\text { [\%] }\end{array}$ & $\begin{array}{c}\text { PERCENTAGE } \\
\text { OF STUDIES } \\
\text { REPORTING } \\
\text { POSITIVE } \\
\text { INFLUENCE OF } \\
\text { INTEGRATION ON } \\
\text { COSTS [\%] }\end{array}$ \\
\hline $\begin{array}{l}\text { Change of relations between service providers } \\
-\quad \text { structural relations between providers, including } \\
\text { co-location, case management, multidisciplinary teams }\end{array}$ & 65.5 & 66.7 & 16.7 \\
\hline $\begin{array}{l}\text { Coordination of clinical activities } \\
-\quad \text { structural solutions coordinating the delivery } \\
\text { of health services between care providers, including joint } \\
\text { consultations, patients' health evaluation, making priority } \\
\text { appointments at subsequent care providers }\end{array}$ & 61.3 & 33.3 & 20.0 \\
\hline $\begin{array}{l}\text { Improvement of communication between care providers } \\
\text { - case consultations, tele-conferences }\end{array}$ & 55.3 & 54.5 & 14.3 \\
\hline $\begin{array}{l}\text { Activities supporting and controlling personnel } \\
\text { - joint training courses, the system of reminders }\end{array}$ & 57.1 & 57.1 & 8.3 \\
\hline $\begin{array}{l}\text { Implementation of IT and communication systems } \\
\text { - treatment plans, availability of patients' records in service } \\
\text { providers' network, electronic patients' register }\end{array}$ & 60.5 & 36.8 & 15.4 \\
\hline $\begin{array}{l}\text { Activities supporting patients } \\
\text { - education, assistance in access to services, system } \\
\text { of reminders }\end{array}$ & 35.3 & 50.0 & 14.3 \\
\hline Total (all available papers and studies) & 55.4 & 45.2 & 17.9 \\
\hline
\end{tabular}

Source: own work on the basis of (Ling et al., 2010, p. 2; Powell-Davies et al., 2008, pp. 65-68).

In the study of Powell-Davies' team, better results were achieved with regard to patient satisfaction indicator: a percentage of randomized studies reporting positive influence on the indicator in respect of multiple strategies was at least $50 \%$. Poorer results in this regard were obtained in the case of coordination of clinical activities and the implementation of IT and communication system (Tab. 2). Integrated care programmes have had relatively the widest impact on the health status of integrated programmes of chronic disease management. That analysis indicated the improvement in patient satisfaction in $71 \%$ of studies, the improvement of patients' clinical condition in $45 \%$ of studies and the improvement of cost efficiency in 16\% of studies (Ofman et al., 2004, pp. 182-192). The results obtained by other researchers are even more curious and thought-provoking, as the influence of integrated health care on cost effectiveness is ambiguous (McDonald, 2007, pp. 65-66). Therefore, 
the issue of effectiveness of mechanisms coordinating and integrating health care in terms of effectiveness objectives needs to be approached with caution.

Apart from the three main directions of integrated health care evaluation referred to above, many more can be found in literature, including the ones evaluating „soft” elements, such as employees' satisfaction, or the quality of teamwork. However, as G. Armitage's team argues on the grounds of a systematic literature review, the majority of reports are based on perceived benefits of health care integration, and not on empirically verified data (Armitage et al., 2009, pp. 1-11). The systematic effects of the implementation of integrated systems of delivering health care, both with regard to financial and economic management of the studied institutions, as well as to „soft” elements, such as organisational culture or inter-organisational communication.

The above systematic literature review encompasses the multidisciplinary knowledge based on the research and thorough methodological approach. The concentration on the system-level integration could be treated as a limitation, as programme-level studies were not targeted.

Overall, the presented systematic literature reviews highlight some models, measurement instruments,

Tab. 3. Effects of integrated health care according to systematic literature review conducted by Armitage's team

\begin{tabular}{|c|c|c|}
\hline METHODS OF MEASUREMENT & SUBJECT OF MEASUREMENT & OBTAINED RESULTS \\
\hline Questionnaires with managers & $\begin{array}{l}\text { Degree of functional integration along } \\
\text { with the management of finances }\end{array}$ & $\begin{array}{l}\text { Better financial results in comparison } \\
\text { to the competition }\end{array}$ \\
\hline $\begin{array}{l}\text { Questionnaires, interviews and focus } \\
\text { groups with staff and managers }\end{array}$ & $\begin{array}{l}\text { Experiences of the personnel involved } \\
\text { in the system of integrated delivery of } \\
\text { health care services }\end{array}$ & $\begin{array}{l}\text { Positive effects regarding: } \\
\text { employee satisfaction, teamwork, } \\
\text { communication, inter-organisational } \\
\text { cooperation, organisational culture }\end{array}$ \\
\hline $\begin{array}{l}\text { Data from annual surveys, uniform } \\
\text { data system }\end{array}$ & $\begin{array}{l}\text { Consumption of resources of hospitals } \\
\text { and health centres in the network of } \\
\text { cooperating entities }\end{array}$ & $\begin{array}{l}\text { Reduction of unplanned admissions } \\
\text { of chronically ill patients to } \\
\text { "emergency" admission room. } \\
\text { A decrease in the indicator of the } \\
\text { average length of hospital stay }\end{array}$ \\
\hline $\begin{array}{l}\text { Interviews, questionnaires, non- } \\
\text { participant observation of primary } \\
\text { health care providers }\end{array}$ & $\begin{array}{l}\text { Management and clinical practices } \\
\text { used in a local network of service } \\
\text { providers }\end{array}$ & $\begin{array}{l}\text { Reduction of unit cost of appointment } \\
\text { (per patient) within the network. } \\
\text { More horizontal organisational } \\
\text { structure }\end{array}$ \\
\hline Data from annual surveys & $\begin{array}{l}\text { Financial management of county } \\
\text { hospitals (case of clinical structural } \\
\text { integration) }\end{array}$ & $\begin{array}{l}\text { Lack of explicit improvement of } \\
\text { financial results, ambiguous result }\end{array}$ \\
\hline $\begin{array}{l}\text { Data from annual surveys and } \\
\text { disclosure reports, health care } \\
\text { financial administration, area } \\
\text { resource file }\end{array}$ & $\begin{array}{l}\text { Financial management of integrated } \\
\text { network of short-term hospital }\end{array}$ & $\begin{array}{l}\text { Positive influence on the financial } \\
\text { indicator }\end{array}$ \\
\hline
\end{tabular}

Source: own work on the basis of (Armitage et al., 2009, p. 6).

literature review of this case covered the total of 219 studies, which considered integrated methods of delivering health care. Selected studies concerned the United Kingdom, the USA, Australia, New Zealand and Canada. The studies were selected using the following keywords "delivery of health care, integrated”, „organisational integration” and „integrated delivery systems, health care”, using a number of databases, including ABI Global, MEDLINE, EMBASE, PsycInfo and Business Source Premier. The review concerned the literature of 19962006.

Below, only those works are presented, which constituted randomized empirical tests, reporting and outcomes of integration which may be helpful for planners and decision-makers of integrated health systems.

\section{CONCLUSIONS}

The above empirical reports as well as descriptive studies provide us with the very interesting research material. They show the three main dimensions that allow us to evaluate the performance of integrated health care delivery systems. The applied dimensions for the evaluation of integrated health care refer mainly to the American health system. A few of these 
instruments have been adapted to European conditions, including those of several European Union countries. The tools as well as their accompanying procedural methodologies feature several elements that constitute certain limitations for their direct adaptation to other health care systems, such as the Polish health care system.

Firstly, the available dimensions of evaluating quality and efficiency in integrated health care refer to the experiences of patients and managers with that type of health care service provision model. Therefore, they cannot be applied in systems that are at an early stage of its implementation, or which do not feature the model at all. An important reason for the need to create new measurement instruments is not merely organisational differences, but social and cultural ones as well.

Secondly, the dimensions discussed above refer to different systemic solutions, which mean that the organisation of healthcare systems providing the background for the afore-mentioned measurement instruments differs from the one that WHO proposes for the region of Europe, including Poland. Above all, it concerns the integration of health service financing and provision that operates in the USA and the integration of only the process of service provision proposed by WHO in Europe.

Thirdly, the methodology developed in the United States was built on the basis of scientific evidence gathered by American service providers. However, it does not mean that such achievements could be directly used in the European setting.

\section{LITERATURE}

Armitage, G., Suter, E., Oelke, N., \& Adair, C. (2009). Health systems integration: state of the evidence. International Journal of Integrated Care, 9(2), 1-11. doi: $10.5334 /$ ijic. 316

Badamgarav, E., Croft, J. D. Jr, Hohlbauch, A. et al. (2003). Effects of disease management programs on functional status of patients with rheumatoid arthritis. Arthritis Care \& Research, 49(3), 377-387. doi: 10.1002/ art.11120

Berenson, R., \& Howell, J. (2009). Structuring, financing and paying for effective chronic care coordination. A report commissioned by the National Coalition on Care Coordination, Urban Institute.

Bravata, D. M., McDonald, K. M., Shojania, K. G., Sundaram, V., \& Owens, D. K. (2005). Challenges in systematic reviews: synthesis of topics related to the delivery, organization, and financing of health care. Annals of Internal Medicine, 142(12 Pt 2), 1056-1065.
Brereton, P., Kitchenham, B. A., Budgen, D., Turner, M., \& Khalil, M. (2007). Lessons from applying the systematic literature review process within the software engineering domain. The Journal of Systems and Software, 80(4), 571-583. doi:10.1016/j. jss.2006.07.009

Brown, R. (2009). The promise of care coordination. Report commissioned by the National Coalition for Care Coordination. Overview of Current Initiatives, Mathematica Policy Research, Inc.

Ferguson, J. A., \& Weinberger, M. (1998). Case management programs in primary care. Journal of General Internal Medicine, 13(2), 123-126. doi: 10.1046/j.15251497.1998.00029

Feussner, J. R., Kizer, K. W., \& Demakis, J. G. (2000). The quality enhancement research initiative (QUERI): from evidence to action. Medical Care, 38, I1-I6. doi: 10.1097/00005650-200006001-00001

Hardy, B., Van Raak, A., Mur-Veeman, I., Steenbergen, M., \& Paulus, A. (2003). Introduction. In A. Van Raak, I. Mur-Veeman, B. Hardy, M. Steenbergen, \& A. Paulus (Eds.), Integrated care in Europe. Description and comparison of integrated care in six $E U$ countries. Maarssen, The Netherlands: Elsevier Gezondheidzorg.

Kodner, D. L., \& Spreeuwenberg, C. (2002). Integrated care: meaning, logic, applications and implications: a discussion paper. International Journal of Integrated Care, 2(e12). Retrieved from http://www.ncbi.nlm. nih.gov/pmc/articles/PMC1480401/

Lavis, J. N., Davies, H., Gruen, R. L., \& Walshe, K. (2006). Working within and beyond the Cochrane Collaboration to make systematic reviews more useful to healthcare managers and policy makers. Healthcare Policy, 1(2), 21-33.

Lavis, J. N., Davies, H., Oxman, A., Denis, J., GoldenBiddle, K., \& Ferlie, E. (2005). Towards systematic reviews that inform health care management and policy-making. Journal of Health Services Research and Policy, 10(Suppl 1), 35-48. doi: 10.1258/1355819054308549

Leutz, W. (1999). Five laws for integrating medical and social services: lessons for the United States and the United Kingdom. The Milbank Quarterly, 77(1), 77110. doi: 10.1111/1468-0009.00125

Ling, T., Bardsley, M., Adams, J., Lewis, R., \& Roland, M. (2010). Evaluation of UK integrated care pilots: research protocol. International Journal of Integrated Care, 10(e056). Retrieved from http://www.ncbi.nlm. nih.gov/pmc/articles/PMC2948682/

Lomas, J. (2005). Using research to inform healthcare managers' and policy makers' questions: from summative to interpretive synthesis. Healthcare Policy, 1(1), 55-71.

McAlister, F. A., Lawson, F. M., Teo, K. K., \& Armstrong, P. W. (2001a). A systematic review of randomized trials of disease management programs in heart failure. American Journal of Medicine, 110(5), 378-384. doi: 10.1016/S0002-9343(00)00743-9

McAlister, F. A., Lawson, F. M., Teo, K. K., \& Armstrong, P. W. (2001b). Randomised trials of secondary prevention programmes in coronary heart disease: systematic review. British Medical Journal, 323(7319), 
957-962.

McDonald, K. M, Vandana Sundaram, M. M., Dena, M. P., Bravata, M. et al. (2007). Closing the Quality Gap: a critical analysis of quality improvement strategies, AHRQ Publication No. 04 (07)-0051-7. Standford: Stanford University, Evidence-based Practice Center.

Moser, D. K. (2000). Heart failure management: optimal health care delivery programs. Annual Review of Nursing Research, 18(1), 91-126.

Mur-Veeman, I., Van Raak A., \& Paulus, A. (2008). Comparing integrated care policy in Europe: does policy matter? Health Policy, 85(2), 172-183. doi: 10.1016/j.healthpol.2007.07.008

Norris, S. L., Nichols, P. J., Caspersen, C. J., et al. (2002). The effectiveness of disease and case management for people with diabetes. A systematic review. American Journal of Preventive Medicine, 22(4, Suppl. 1), 15-38. doi: 10.1016/S0749-3797(02)00423-3

Ofman, J. J., Badamgarav, E., Henning J. et al. (2004). Does disease management improve clinical and economic outcomes in patients with chronic diseases? A systematic review. American Journal of Medicine, 117(3), 182-192. doi: 10.1016/j.amjmed.2004.03.018

Philbin, E. F. (1999). Comprehensive multidisciplinary programs for the management of patients with congestive heart failure. Journal of General Internal Medicine, 14(2), 130-135.

Powell Davies, G., Williams, A., Larsen, K., Perkins, D., Roland, M., \& Harris, M. (2008). Coordinating primary health care: an analysis of the outcomes of a systematic review. Medical Journal of Australia, 188(8), 65-68.

Renders, C. M., Valk, G. D., Griffin, S., Wagner, E. H., Eijk, J. T., \& Assendelft, W. J. (2001). Interventions to improve the management of diabetes mellitus in primary care, outpatient and community settings. Cochrane Database of Systematic Reviews, 1(CD001481).

Rich, M. W. (1999). Heart failure disease management: a critical review. Journal of Cardiac Failure, 5(1), 6475. doi: 10.1016/S1071-9164(99)90026-X

Rudawska, I. (2013). Methodology of assessing patient service quality in integrated healthcare - a preliminary framework. Actual Problems of Economics, 9(147), 481-491.

Sin, D. D., McAlister, F. A., Man, S. F., \& Anthonisen, N. R. (2003). Contemporary management of chronic obstructive pulmonary disease: scientific review. The Journal of the American Medical Association, 290(17), 2301-2312. doi:10.1001/jama.290.17.2301

Sobczak, A., \& Grudziąż-Sękowska, J. (2011). Zwiększanie efektywności opieki zdrowotnej przez płacenie za wyniki - specyfika, przykłady i warunki skutecznego zastosowania [Enhancing health care efficiency through paying for performance - specifics, examples and conditions of effective application]. Problemy Zarzadzania, 9(3), 153-168.

Stranberg-Larsen, M., \& Krasnik, A. (2009). Measurement of integrated healthcare delivery: a systematic review of methods and future. International Journal of Integrated Care, 9(1), 1-10. doi: 10.5334/ijic.305
SUTC - Stroke Unit Trialists' Collaboration. (2007). Organised inpatient (stroke unit) care for stroke. Cochrane Database of Systematic Reviews, 17(4, CD000197).

Van Raak, A., Mur-Veeman, I., Hardy, B., Steenbergen, M., \& Paulus, A. (Eds.). (2003). Integrated care in Europe. Description and comparison of integrated care in six EU countries. Maarssen, The Netherlands: Elsevier Gezondheidzorg.

Vondeling, H. (2004). Economic evaluation of integrated care: an introduction. International Journal of Integrated Care, 4(e20). Retrieved from http:// www.ncbi.nlm.nih.gov/pmc/articles/PMC1393259/

Windham, B. G., Bennett, R. G., \& Gottlieb, S. (2003). Care management interventions for older patients with congestive heart failure. American Journal of Managed Care, 9(6), 447-459. 